IZA DP No. 5522

Nowcasting Business Cycles Using Toll Data

Nikolaos Askitas

Klaus F. Zimmermann

February 2011 


\title{
Nowcasting Business Cycles Using Toll Data
}

\author{
Nikolaos Askitas \\ IZA \\ Klaus F. Zimmermann \\ IZA and University of Bonn
}
Discussion Paper No. 5522
February 2011

\author{
IZA \\ P.O. Box 7240 \\ 53072 Bonn \\ Germany \\ Phone: +49-228-3894-0 \\ Fax: +49-228-3894-180 \\ E-mail: iza@iza.org
}

\begin{abstract}
Any opinions expressed here are those of the author(s) and not those of IZA. Research published in this series may include views on policy, but the institute itself takes no institutional policy positions.

The Institute for the Study of Labor (IZA) in Bonn is a local and virtual international research center and a place of communication between science, politics and business. IZA is an independent nonprofit organization supported by Deutsche Post Foundation. The center is associated with the University of Bonn and offers a stimulating research environment through its international network, workshops and conferences, data service, project support, research visits and doctoral program. IZA engages in (i) original and internationally competitive research in all fields of labor economics, (ii) development of policy concepts, and (iii) dissemination of research results and concepts to the interested public.
\end{abstract}

IZA Discussion Papers often represent preliminary work and are circulated to encourage discussion. Citation of such a paper should account for its provisional character. A revised version may be available directly from the author. 
IZA Discussion Paper No. 5522

February 2011

\section{ABSTRACT}

\section{Nowcasting Business Cycles Using Toll Data}

Nowcasting has been a challenge in the recent economic crisis. We introduce the Toll Index, a new monthly indicator for business cycle forecasting and demonstrate its relevance using German data. The index measures the monthly transportation activity performed by heavy transport vehicles across the country and has highly desirable availability properties (insignificant revisions, short publication lags) as a result of the innovative technology underlying its data collection. It is coincident with production activity due to the prevalence of just-in-time delivery. The Toll Index is a good early indicator of production as measured for instance by the German Production Index, provided by the German Statistical Office, which is a well-known leading indicator of the Gross National Product. The proposed new index is an excellent example of technological, innovation-driven economic telemetry, which we suggest should be established more around the world.

JEL Classification: $\quad$ C82, E01, E32, E37, L92

Keywords: business cycles, data mining, evaluating forecasts, macroeconomic forecasting, new products, transportation, production forecasting, nowcasting, telemetry

Corresponding author:

Nikolaos Askitas

IZA

P.O. Box 7240

53072 Bonn

Germany

E-mail: askitas@iza.org

\footnotetext{
* The authors thank Juergen Triebel and Susanne Attin of the Bundesamt fuer Gueterverkehr for their invaluable help in obtaining and interpreting the data.
} 


\section{Introduction}

Nowcasting of important business cycle indicators, such as the Gross Domestic Product (GDP), is based on data series often susceptible to various pathologies, some of which include: (i) mixed data sampling (see for example Ghysels et al. (2007), Schumacher \& Breitung (2008)); (ii) significant publication lags (the variance of which leads to the so-called ragged-edge problem in multivariate analysis, see for example Wallis (1986), Ferrara et al. (2010)); as well as (iii) several revisions which lead to several vintages of the data series which are a subject matter of investigation themselves (see for example Stark \& Croushore (2002)). All of these problems create quality or feasibility issues in forecasting and much of the literature is devoted to dealing with them through elaborated econometric techniques. It is against this backdrop of data issues when analysts are called upon to provide fast and reliable nowcasts to policy makers, central bankers and other decision makers to support their effective policy decisions.

In this paper we take a complementary route which has not been sufficiently explored in the literature (Bodo et al. (1991) is similar in spirit to our paper). While trying to remedy data pathologies is a natural thing to do (and our work will not be completely immune to its own issues), we believe that given the technological advances of the last couple of decades, it is a viable path to try exploring new data sources and data acquisition methods which may be immune to some of the problems data have had so far. By applying our understanding of the new economic and technological realities, we try to imagine what kind of data could relate well to GDP or its leading indicators while having better availability properties. We indeed suggest a new leading indicator based on data potentially available in real-time on an even daily basis, due to the innovative technology underlying its collection (the need for new indicators in forecasting German Industrial Production is one of the conclusions of Robinzonov \& Wohlrabe (March 2008)). Furthermore the data have a maximum of two vintages with negligible differences. The vision is that with the technology currently available we should be able to obtain data without publication lags or significant vintages and that done well, one could provide telemetry or diagnostics of the current state of the economy in near real-time. What we believe we should strive for is economic diagnostics which will answer the question of what is happening in the economy now. ${ }^{1}$ This is what is known in the literature as nowcasting. Nowcasting is a meteorological term first used for economics in Giannone et al. (2008). 
The central idea of this paper for nowcasting is that since GDP is an expression of a country's economic output, it should be highly correlated with transportation activities of goods, at least to the extend to which it consists of physical goods. The part of GDP which comes from the service sector may be related to, but does not necessarily cause, transportation activities.

In Germany a toll collection system known as MAUT was established in 2005 and its measurements may proxy transportation activities. All commercial vehicles over 12 tons are obliged to pay toll. For trucks which travel on German highways frequently the MAUT system provides an On Board Unit (OBU). This system works on the basis of the Global Positioning System (GPS) and the Global System for Mobile Communications (GSM) in order to determine kilometers travelled on German highways and transmit the measurements to a central billing center respectively. Measurements of transportation activities based on the MAUT system are therefore good candidates for the suggested monthly production indicator, which we will call the Toll Index (TI). As a proxy for the monthly production we use the monthly Produktionsindex im Produzierenden Gewerbe or the German Production Index (GPI), produced by the German Statistical Office (DESTATIS), which is a well-known leading indicator of GDP in its own right. Since just-in-time production implies goods are stored in the distribution chain, making the warehouse largely obsolete, and since technology simplifies plotting truck trips in real time, the TI should be an effective nowcast of production.

This is important, since the TI is known about a month in advance of the GPI and it nowcasts it well. We suggest that MAUT technology can be used worldwide to establish a live telemetry system of economic activity. We should mention here that we focus less on elaborate modeling and more on innovative choice of explanatory data and that in fact one of the main points of our paper is that innovative data with simple modeling can be very effective. As shown in Robinzonov \& Wohlrabe (March 2008) "it is nearly always possible to find situations in which one indicator proved to have better predicting power compared to another". The paper is organized as follows: in section 2 we present the data methodology and section 3 discusses data issues. Section 4 presents the empirical findings and section 5 concludes.

\section{Data Methodology}

In this section we describe the background of the data used. We introduce the GPI, the German highway truck toll system, define the TI and compare it to the GPI. We also discuss data 
shortcomings. The GPI measures the monthly performance of the productive industrial sector in Germany. Due to its periodicity, its quick availability and its sector granularity, it is a significant leading indicator of the business cycle. Each month the state-level statistical offices collect data about the amount and value of output from 6,000 industrial units with at least 50 employees. These industrial units represent about $80 \%$ of the country's industrial output. On the 25 th of the following month this data is passed on to the Federal Statistical Office, where several measures of production are calculated using the average of all months in 2005 as the reference value to normalize it to 100 . The result of the preliminary computation of the monthly production index is published around 38 days after the end of the reported month in a press release of the Federal Ministry of Economics and Technology, together with an evaluation of the current economic situation, but may be revised in the following months.

The truck toll system with its GPS support and GSM based real-time data communications is a well-designed modern toll collection system. It was introduced in Germany in 2005 as a highway truck toll system for heavy goods vehicles over 12 tons. Its purpose is to secure a steady flow of revenue to support improvements in infrastructure. Its global coverage, automatic computation, fast data transmission and centralized data collection allows us to think of the MAUT as a countrywide network of sensors producing economic telemetry. In fact it is the first example we know which makes the economic analogue of a tick data stream (known from the finance world) look like a realistic goal, even on a daily basis. This is quite possibly as close as anyone has ever come to a live telemetry system of economic activity.

According to system operator Toll Collect GmbH, five years after the system was installed nearly 900,000 heavy goods vehicles owned by 127,000 haulage companies in 41 countries have registered. Some 642,000 vehicles are equipped with OBUs for automatic toll collection. The proportion of foreign-owned vehicles with OBUs has increased to 42 percent. According to the systems operator "over the past five years, the German toll system has logged and invoiced around 140 billion kilometers more than any other toll system anywhere in the world. The satellite-supported toll system has been widely accepted by German and foreign users alike. This is especially true for the automatic log-on system using OBUs. In January 2005, automatic log-on accounted for 72 percent of all toll bookings. Today, this figure has risen to more than 90 per cent". ${ }^{2}$ Besides using an OBU, truck drivers can pay at designated terminals or over the internet. Since data transmission is made 
via GSM over public networks, data communications are encrypted and the detailed data is used strictly for billing purposes and deleted soon after the billing statement is settled.

Our data comes from the monthly reports of the German Federal Office for Goods Transport (BAG), which contain public aggregate data of the truck toll system. These reports contain information on the number of inbound and outbound vehicles for all exits (country and highway) as well as information on the travel activity per vehicle country of origin. We were able to obtain monthly aggregates of these numbers for the years 2007 to 2010; the data for the years 2005 and 2006 are apparently unrecoverable. ${ }^{3}$

For the purposes of this paper and in order to facilitate the discussion among practitioners, we will scale any variant of the TI which is proposed to nowcast the GPI, so that the GPI and the TI are identical in the first month they are simultaneously available, i.e. January 2007. We will in fact restrict our attention to four variants of the TI: one expressing distance traveled, one expressing number of trips, and one each for numbers of inbound and outbound vehicles. We will then refer to the distance, trip, inbound and outbound components of the TI respectively.

\section{Data Issues}

Produced physical goods need to be delivered. This means goods delivery/transportation aggregates are close to production itself. The measurements of production and transportation though as expressed by the GPI and the TIs are susceptible to certain shortcomings. The possible shortcomings of the GPI as an early indicator of production come from the fact that voluntary self-reporting may be of varying accuracy and from sampling: small production units representing about 20 percent of total German production, are not taken into account. The possible shortcomings of the GPI as an early indicator of GDP come from the varying share of production itself in GDP versus for example the outcomes of the services or construction sectors. In the same manner the TI has shortcomings as a measure of the total goods transportation activities by the fact that while the MAUT is an excellent technological network of sensors, it only senses trucks over 12 tons. We know for example (see Evangelinos (2009)) that according to data by the BAG there has been a significant increase in truck registrations in the class 10-12 tons (i.e. the largest class not in the MAUT) following the introduction of the MAUT. The high correlation of the two may well be generated by the fact that large production units use large transport vehicles.

Products are transported by rail, air and on waterways. Therefore truck transportation is only 
one of many ways by which products are delivered and is therefore not exclusive but, like other transport methods will be sensitive to business cycle fluctuations. The number of trucks crossing the German borders may not be representative of the trade volumes with the neighboring countries, a fact which may be due to the multitude of ways goods are transported, the nature of goods traded or the fact that trucks will pass through many countries before reaching their final destination.

The data available do not allow us to distinguish between trucks which pass through and those whose destination is Germany. The data has further deficits, as can be seen by the example of France, which is the largest trading partner of Germany and has only one toll highway. This is of course not the only highway connecting the two countries, but it is the only highway between the two countries without a MAUT waiver. ${ }^{4}$ According to data by DESTATIS (see Liedtke \& Ott (2006)) on the market share of different transport modes for international freight transport, road transportation covers about 60 percent of the transportation with waterways about 30 percent and rail about 10 percent. This means that MAUT data should have a good chance of capturing a good portion of the trade variation. The availability of the MAUT data is like a dream come true for a data professional as it provides unprecedented, near live telemetry of economic activity. It is spoiled only by the fact that unfortunately the system has yet to be used to its full potential. Given the advanced technology which underlies the MAUT, it would be technically possible to produce aggregates on a weekly or even daily basis. In its current implementation MAUT data is made public on a monthly basis with a three-week publication lag, which given the underlying technology can definitely be improved.

\section{Empirical Findings}

Our basic empirical findings on the data are summarized in Figures 1 and 2. Figure 1 depicts the percentage of change over the previous month for the variants of TI and the GPI, and Figure 2 presents the annual percentage changes of the same measures. We clearly see that both the month over month and the year over year differences of the monthly vehicle activity relate well with those of the monthly production index. Therefore the TIs reflect well the seasonality pattern dominating the monthly changes as well as the more long-run trends filtered out by the annual changes. In the remainder of this section we will further establish the nowcasting quality of the TI by examining some forecasting models and testing their prediction success using all observations of 2010 as our out of sample time interval. We establish that despite a still fairly short time series we find a good 
out of sample forecasting performance.

We first address some of the issues relevant to the MAUT data and hence to the TIs. We start with the revisions of the MAUT data. There are two vintages for each data point which are not due to any estimates involved in producing the preliminary number, as is usually the case, but due to the fact that trucks which have not cleared their account by a certain date are not counted (although their data is in the system). Revisions therefore are due to the MAUT's revenue orientation and could be easily eliminated for forecasting purposes. The revision of the MAUT data of a month $m$ of a year $y$ is published together with the "preliminary value" of the month $m$ of year $y+1$ in a report of the BAG. Our data comes from the monthly reports of 2008, 2009 and 2010. Hence for 2007 we have revised values only, for 2008-2009 we have preliminary and revised values, and finally for 2010 we have preliminary numbers only.

Let $T I_{x}(x=k, t, i, o)$ be the four variants of the Toll Index based on monthly kilometers travelled $(k)$, trips made $(t)$, inbound $(i)$ and outbound $(o)$ trucks. Let $T I_{x}^{p}$ and $T I_{x}^{r}$ be the series in 2008-2009 constructed by using the preliminary and revised numbers respectively. Table 1 shows the mean revisions as a percentage of the preliminary value for all series in three time intervals, i.e. the mean of $100 \cdot\left|T I_{x}^{p}-T I_{x}^{r}\right| / T I_{x}^{p}$. We observe that in all time frames the differences are negligible. Moreover, we see that the differences become smaller in 2009 compared to 2008, perhaps as a result of adoption and improved operation. In order to better judge the size of these errors we do the same analysis for the GPI and its revisions and find that the mean change as a percentage of the preliminary values equals $2.34 \%$ (we use the preliminary value and its last available revision and none of the intermediate). This is substantially higher than the revision errors found in Table 1 for the TIs; for instance the revision percentages are between $.057 \%$ for the $T I_{t}$ and $.2218 \%$ for the $T I_{o}$ in the interval 2008-2009.

Table 2 contains the summary statistics for several forecasting models we estimate. We look at five single variable models $(K, T, I, O, L)$ of the form $\Delta_{12}\left(\ln \left(G P I_{s}\right)\right)=\alpha \cdot X_{s}+\beta$ where $X_{s}=$ $\Delta_{12}\left(\ln \left(Y_{s}\right)\right)$ for $Y_{s}=T I_{k, s}, T I_{t, s}, T I_{i, s}, T I_{o, s}, L 1\left(\ln \left(G P I_{s}\right)\right)$. L1 is the first lag operator and $s$ is our time variable. Our two-variable model $K \& T$ uses the combination of $T I_{k}$ and $T I_{t}$ whereas our three-variable model uses a combination of $L 1(\ln (G P I)), T I_{k}$ and $T I_{t}$. We see that all models involving the TI variants are better than the baseline autoregressive model $(L)$ in terms of adjusted $R^{2}, \mathrm{AIC}$ and MSE. 
In order to secure the long term accuracy of the TI we need to control for fluctuations in the market share of road transportation compared to that of waterways, air and rail transportation since it may vary due to reasons exogenous to the business cycle. Some of these reasons may be weather, fuel costs, the MAUT system itself (in case for example the government decides to raise MAUT prices and thus make other transport modes cheaper in comparison) or other policy incentives. We can control for this variation fairly well by using the TI itself and in fact we will show that our model $K \& T$ does just that. Our argument is inspired by the one element common to the highway, harbor, airport and railroad landscapes alike: the intermodal container. These containers which are the central element of intermodal freight transport are normed (ISO standardized) transportation units which revolutionized the transportation industry and are designed so that they can be loaded and sealed equally well onto ships, railroad cars, planes, and trucks (hence intermodal).

Our assertion is then the following. Even if, for example, ship transportation were to gain market share on road transportation trucks would have to deliver the containers to the harbor (which would then be further transported by ship). This means that the TI should capture less kilometers travelled by trucks but more short ${ }^{5}$ trips. In other words the short trips of the trucks are irreplaceable and hence immune to market share fluctuations. It follows that by including the monthly ratio of trips made to kilometers travelled $\left(T I_{t} / T I_{k}\right)$ we should be able to capture the fluctuation of the market share fairly well. In view of the fact that we take natural logarithms our model $K \& T$ hence controls for market share variations and in fact performs best as can be seen in Table 2.

Finally we estimate $K \& T, L \& K \& T$ and $L$ using the GPI values until December of 2009 and show their out of sample (2010) performance in Figure 3. The MSEs are .00028725 for $K \& T$, .00027877 for $L \& K \& T$ and .0023026 for $L$. We see that the MSE of our $K \& T$ model is equal to $12.47 \%$ of the MSE of our benchmark $L$ which is nothing but an $A R(1)$. Further computations show that our best model $K \& T$ in fact also beats (in terms of MSE) all $A R(i)$ we tried with $i=1, \ldots, 12$ as well as an $A R M A(12,3)$ (specifying higher parameters for AR and ARMA models has proven futile). We find for example that the MSE of $K \& T, A R M A(12,3)$ and $A R(12)$ are equal to $.00937117, .02696488$ and .02886973 respectively i.e. the MSE of our model is $32.7 \%$ of the MSE of an $A R M A(12,3)$ and $32.46 \%$ of the MSE of an $A R(12)$. This is a strong result because the AR and ARMA models are estimated on data that go back to 1992 (whereas our models use 
MAUT data from no earlier than 2007)! Figure 4 contains the results of this exercise. This shows that the Toll Index is already a powerful tool for forecasting practitioners and policy makers even at this early stage.

\section{Concluding Remarks}

We have shown that we can nowcast the survey-based monthly GPI well using the TI which exploits readily available German MAUT data. Moreover we can do this around one month ahead of time. The GPI is a well known early indicator of the GDP. It, like GDP, undergoes several revisions some of which may produce seriously different vintages of the series. In contrast MAUT data has a maximum of two vintages, which differ minimally (and could perfectly be eliminated by the MAUT system if desired). This makes the TI a good early indicator of the economic cycle. Furthermore the extent to which the prevalence of just-in-time delivery forces the supply chain to replace the warehouse (we store products not in warehouses but in delivery itineraries) the TI is coincident to production and hence represents an accurate and timely picture thereof. With an out of sample forecasting error which cuts the errors of AR and ARMA models by a factor of 3 (even when these latter models are trained on 17 years worth of monthly data) the TI (estimated on just 3 years worth of data) promises to be useful to the transport industry itself, to the banking sector and anyone with a vested interest in short term forecasting besides governmental policy makers. The data necessary to compute a weekly or daily TI should be relatively easy to produce given the innovative technology underlying the MAUT.

Our nowcasting approach is an example of the kind of live telemetry necessary to enable us to know and monitor the state of the economy in real-time. The use of the truck toll data for this purpose was originally unintended, but our work shows us that live economic telemetry is now possible and has in fact been long overdue. The Toll Index has the potential to become a standard early indicator for business cycle forecasters and practitioners. Moreover it can become an internationally used real-time economic indicator if the MAUT system would be applied elsewhere. In that case the TI would have the potential of reflecting volumes of bilateral trades.

Last but not least governments should make secondary data usage into a primary concern by engaging empirical scientists in the projects design. As our example shows policy makers should invest in better and faster data collection in order to help forecasting practitioners produce more reliable results. Given todays computing and networking capabilities our impaired ability to 
nowcast the state of the economy can definitely improve.

\section{References}

Bodo, G., Cividini, A., \& Signorini, L. F. (1991). Forecasting the italian industrial production index in real time. Journal of Forecasting, 10(3), 285-299.

Evangelinos, C. (2009). Mauteinführung, Mauterhöhung und Nutzerreaktionen in Deutschland. Wirtschaftsdienst, $89(8), 558-564$.

Ferrara, L., Gugan, D., \& Rakotomarolahy, P. (2010). Gdp nowcasting with ragged-edge data: a semi-parametric modeling. Journal of Forecasting, 29(1-2), 186-199. URL http://dx.doi.org/10.1002/for.1159.

Ghysels, E., Sinko, A., \& Valkanov, R. (2007). MIDAS Regressions: Further Results and New Directions. Econometric Reviews, 26(1), 53-90.

Giannone, D., Reichlin, L., \& Small, D. (2008). Nowcasting: The real-time informational content of macroeconomic data. Journal of Monetary Economics, 55(4), 665-676.

Liedtke, G. \& Ott, A. (2006). Relevance of the Rail Freight transports on the MAGISTRALE Corridor. IHK Ulm.

Robinzonov, N. \& Wohlrabe, K. (March 2008). Freedom of choice in macroeconomic forecasting: An illustration with german industrial production and linear models. Ifo Working Paper No $5 \%$.

Schumacher, C. \& Breitung, J. (2008). Real-time forecasting of German GDP based on a large factor model with monthly and quarterly data. International Journal of Forecasting, 24(3), 386-398.

Stark, T. \& Croushore, D. (2002). Forecasting with a real-time data set for macroeconomists. Journal of Macroeconomics, $24(4), 507-531$.

Wallis, K. (1986). Forecasting with an econometric model: The 'ragged edge' problem. Journal of Forecasting, 5(1), $1-13$.

\section{Notes}

${ }^{1}$ In a private conversation with Ed Lazear, who in his capacity as the 24th Chair of the Council of Economic Advisors to G. W. Bush between 2006 and 2009, lived in some of the most dramatic moments in the history of the American Economy, we learned that it is indeed very difficult in practice to know what is happening to the economy now and that while in government one tried to get a sense of current economic activity by measuring postal volume along certain paths. This anecdote highlights in our opinion the urgent necessity of progress in data, techniques and technology suitable for pragmatic nowcasting.

${ }^{2}$ Press release from Toll Collect (www.toll-collect.de) of November 252009.

${ }^{3}$ This is symptomatic for government thinking when it comes to data generating projects. We claim that although this system was mainly aimed at generating revenue for infrastructure maintenance it is reasonable to say that a more comprehensive approach should have been taken which should have answered the question: What else can this data be good for? In fact this is a suggestion we would like to see applied more generally: In the same way that publicly funded government projects engage legal experts in their design in order to comply with privacy concerns they should always contain a component on secondary data usage and this component should be designed with the participation of empirical scientists. The component should define the nature of the data retention of the project in order to maximize return on investment and make it useful for scientific purposes.

${ }^{4}$ There is a special agreement between the two countries which basically waives MAUT fees at their border (except for highway B9 Lauterburg). Furthermore the data of incoming and outgoing trucks on border highways with a waiver is not being tracked, since the sole purpose of the MAUT is to collect fees and in these cases there are no fees to collect. This means in counting total numbers of incoming and outgoing vehicles we count totals without German/French border crossings. In counting totals and per truck origin kilometers driven and trips made all trucks are included.

${ }^{5}$ What we call a trip is called a toll ride in the "methodical explanations" of the Toll statistics. (source http://www.bag.bund.de/cae/servlet/contentblob/45886/publicationFile/3368/

Meth_Erlaeuterung_Maut_englisch.pdf.) It is defined as a ride between an entry into and an exit from a Toll highway. For example exiting to load/unload completes what we call a trip. We calculate the mean such trip to be 85.5 kilometers with a minimum of $80 \mathrm{~km}$ and a maximum of $92.1 \mathrm{~km}$ (std deviation 3.1). This means on the average a truck will exit a Toll covered highway after $85.5 \mathrm{~km}$ (to probably reenter right away a few minutes later or after a load/unload/reload/stopover etc). This serves to better appreciate the negative intercept of $\ln \left(T I_{t}\right)$ in the $K \& T$ 
model: For fixed kilometers as trips move towards the upper end of the interval [80,92.1] the German Production drops. We interpret this is as follows: in times of low business activity trucks need to scramble more to get work causing them to go in and out of the Toll highways more frequent. The interval of values of the toll rides will, in the long run, characterize the German Highway System. To get a better appreciation of this interval looking at the highway A3, which cuts Germany diagonally (NW/SE) in half from the Netherlands to the Austrian border one would have an exit possibility on the average every $5.6 \mathrm{~km}$. The shortest distance between two such exits being 1 $\mathrm{km}$ and the longest $16 \mathrm{~km}$ (standard deviation $3.46 \mathrm{~km}$ ). The total kilometers is about $763 \mathrm{~km}$ and the number of exits equals 135. Data for these calculations come from http://www . autobahnatlas-online.de/. 
Month over Month: 2007-2010
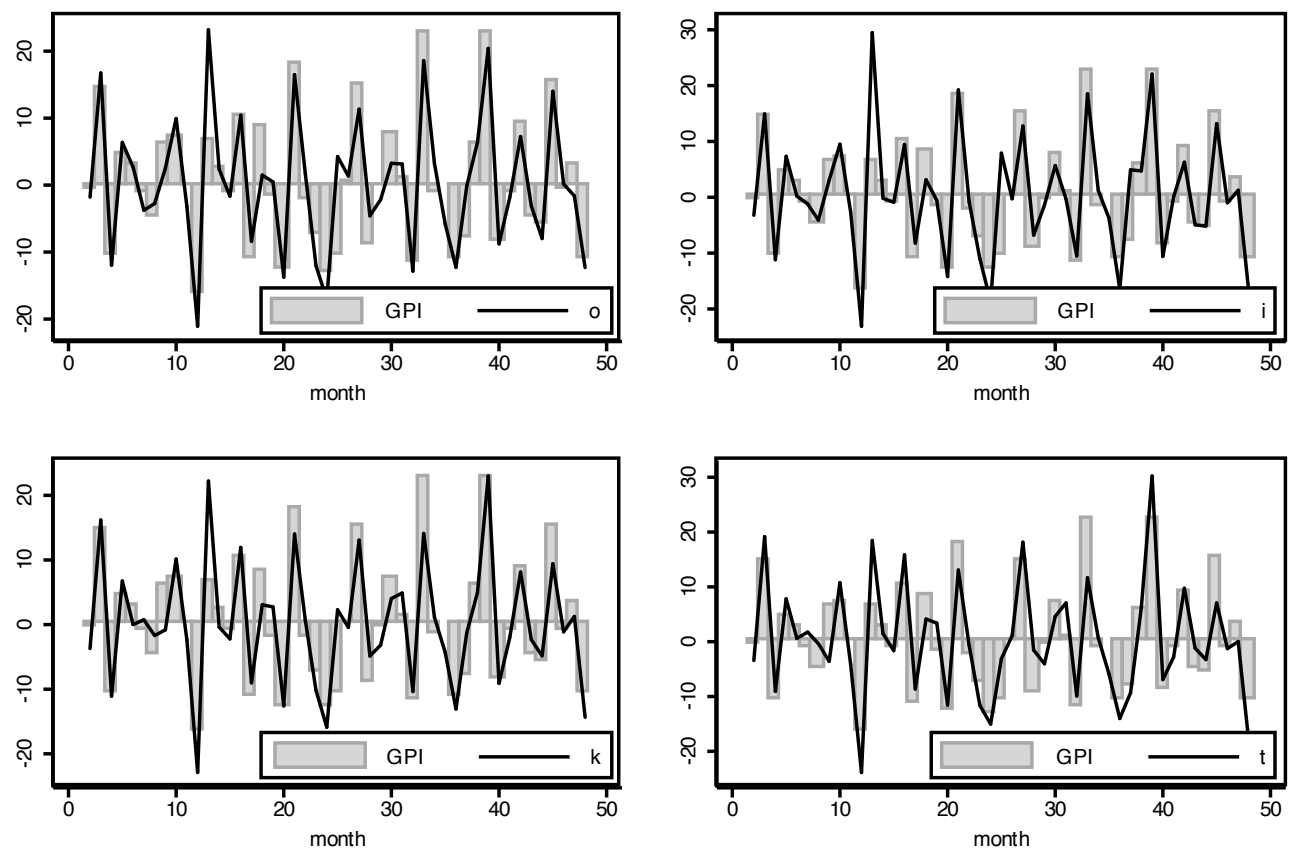

Figure 1: Percentage of change over the previous month for the GPI and the variants of TI (o, i, t,k). 
Year over Year: 2007-2010
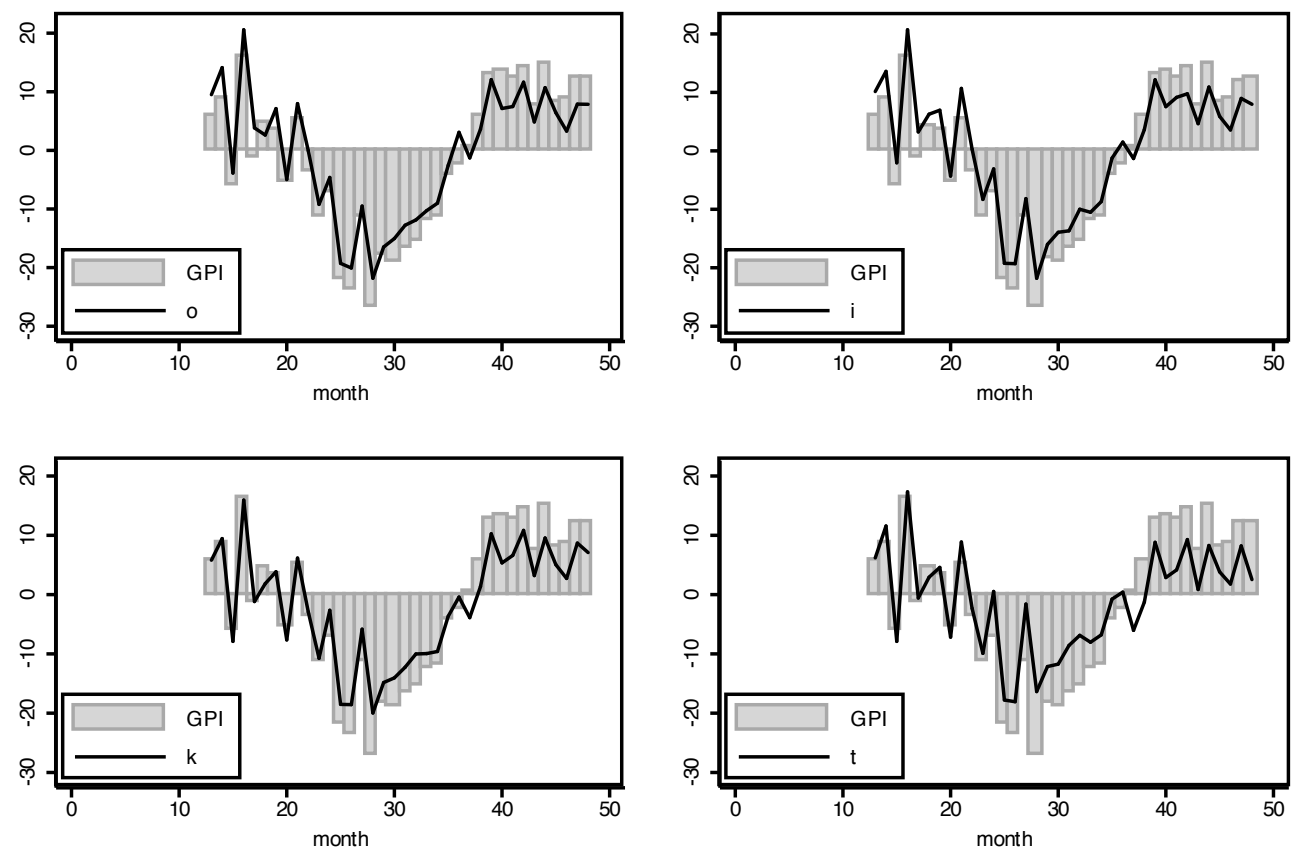

Figure 2: Annual percentage change for the GPI and the variants of TI $(\mathrm{o}, \mathrm{i}, \mathrm{t}, \mathrm{k})$ 


\begin{tabular}{|r|rrrrr|}
\hline \multicolumn{7}{|c|}{ TI data revisions in \% } \\
\hline & \multicolumn{1}{|c|}{$x=i$} & $x=o$ & $x=k$ & $x=t$ \\
\hline \hline \% of change & $2008-2009$ & .0821 & .23 & .1 & .057 \\
& 2008 & .151 & .375 & .177 & .075 \\
& 2009 & .0133 & .064 & .012 & .038 \\
\hline
\end{tabular}

Table 1: Mean change necessary, as a percent of the preliminary value, to go from preliminary values to revised one for all TI variants $(x=k, t, i, o)$ over three different time frames (2008-2009, 2008, 2009). The GPI data revision in 2008-2009 equals $2.59 \%$ in comparison. 


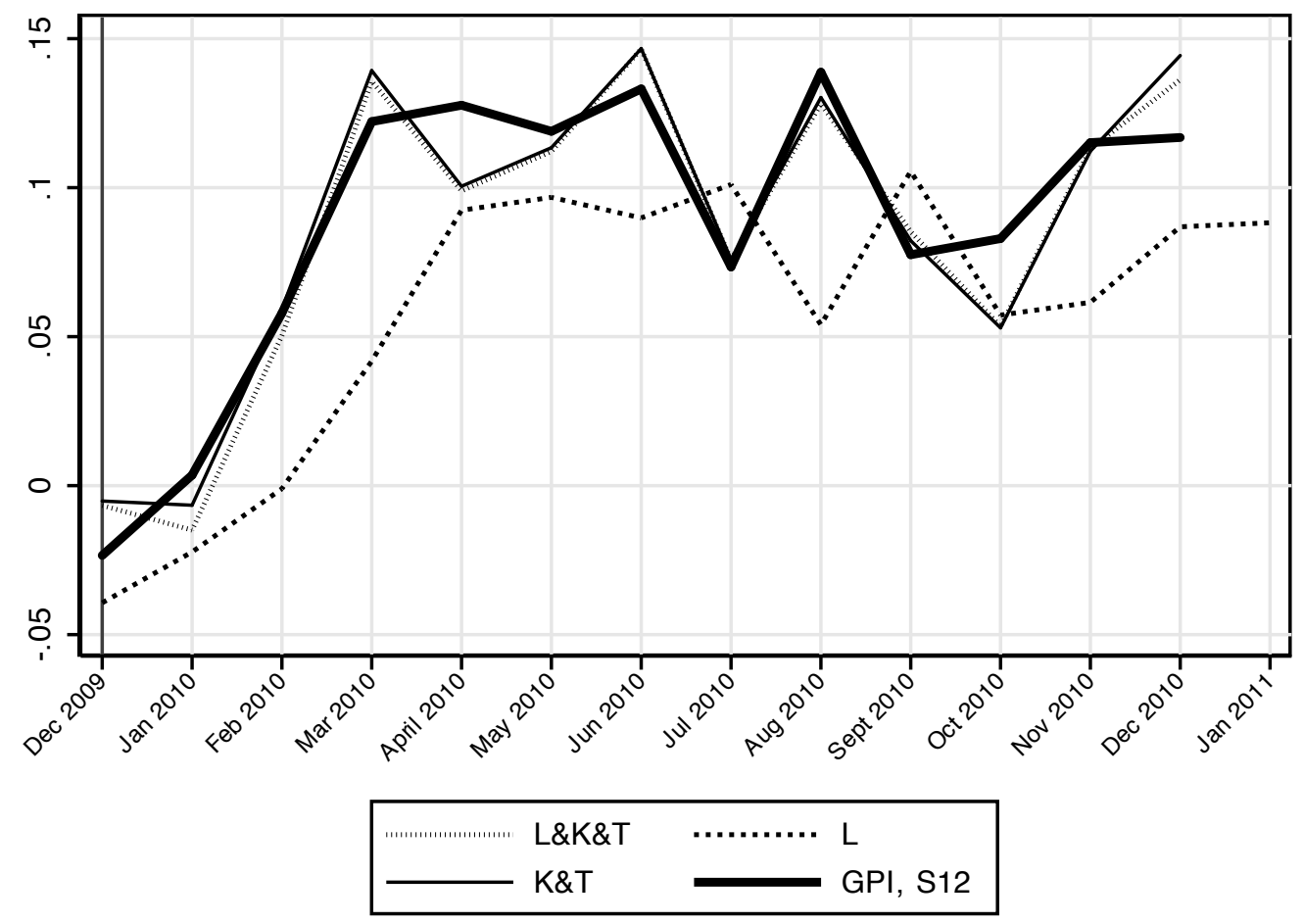

Figure 3: Out of sample performance of TI models (model $K \& T$ using $T I_{k}$ and $T I_{t}$ and model $L \& K \& T$ using $L 1(G P I), T I_{k}$ and $T I_{t}$ ) vs the basic autoregressive model ( $L$ using $L 1(G P I)$ ). The TI based forecasting models clearly outperform the baseline autoregressive model. 


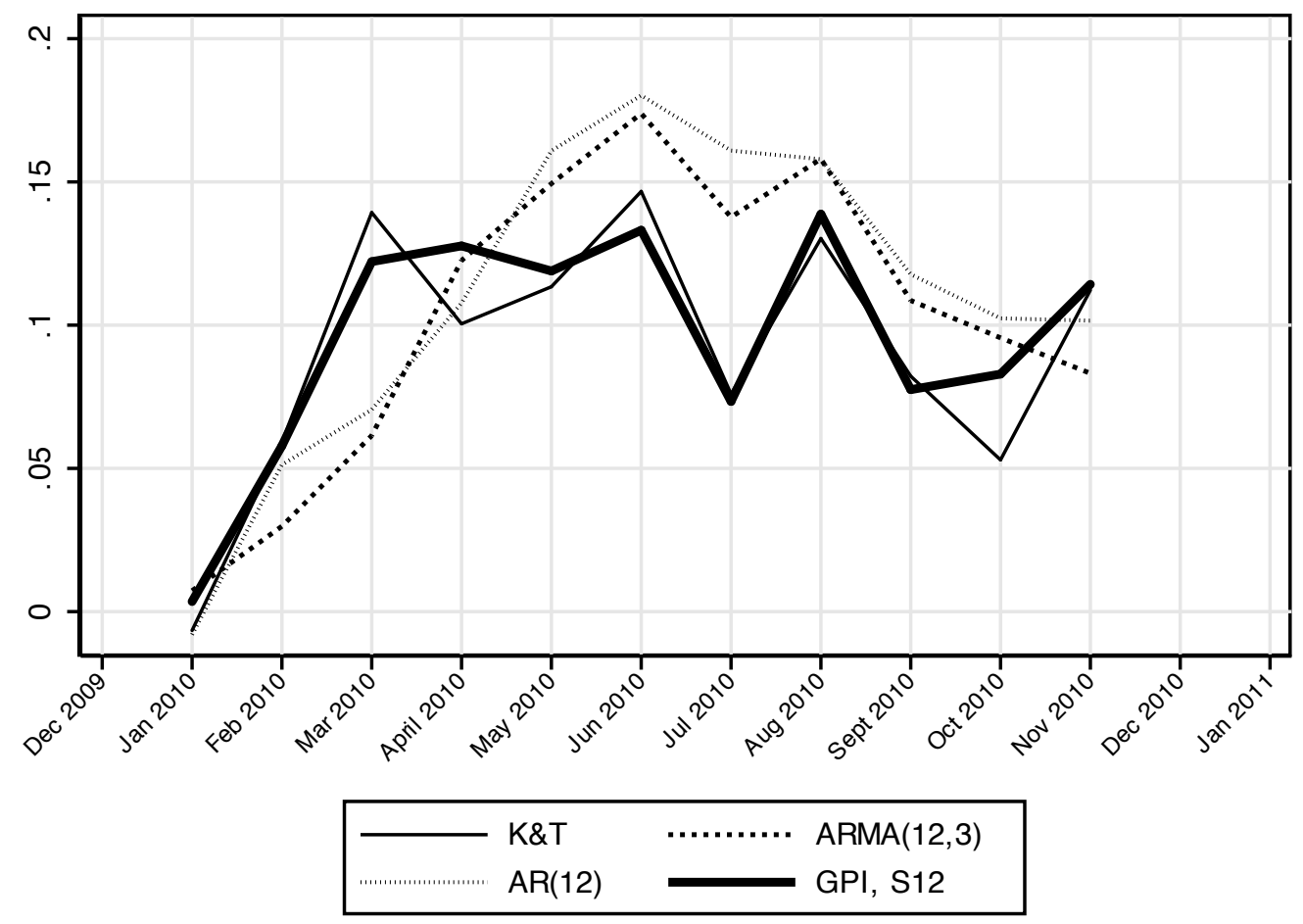

Figure 4: Out of sample performance of the TI model $K \& T$ (which uses $T I_{k}$ and $T I_{t}$ ) and $A R(12)$ and $A R M A(12,3)$. The TI based forecasting models clearly outperform the AR and ARMA models despite the disadvantage of being estimated on much less data. 


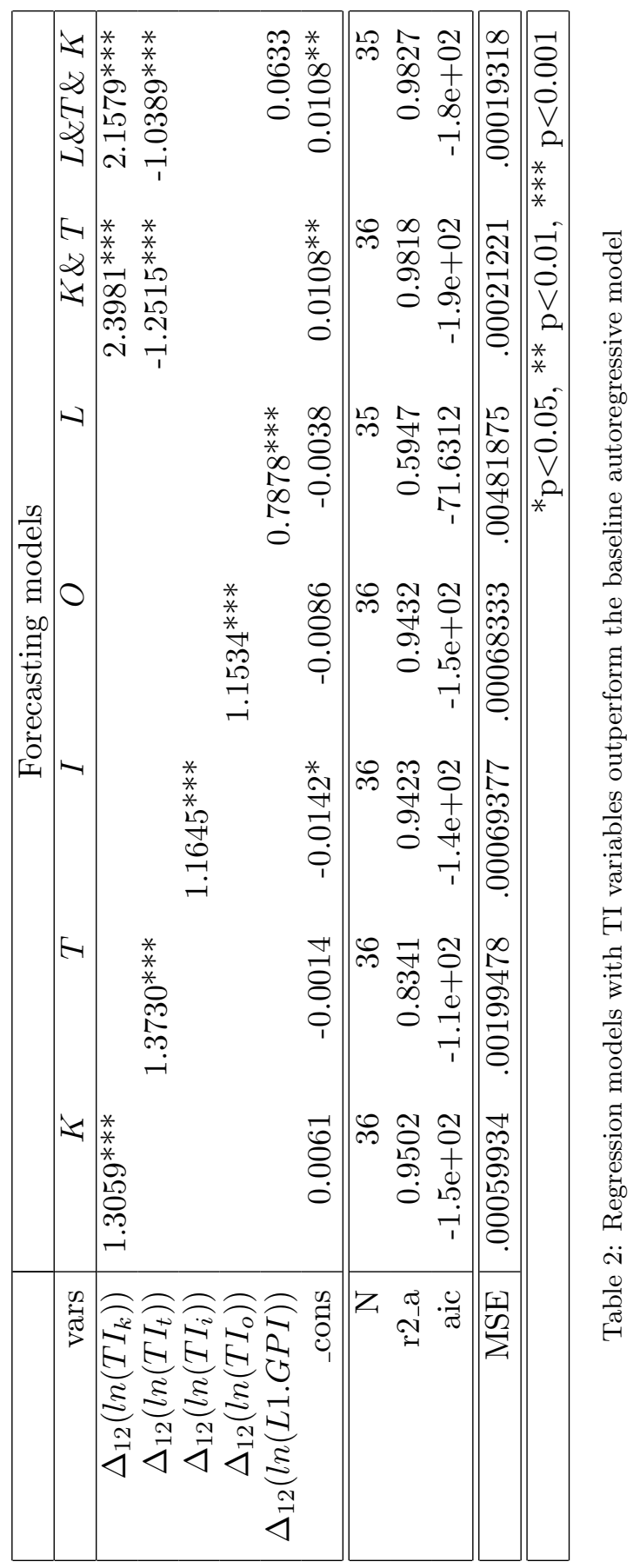

